\title{
RUMOS PARA O ENSINO DE SEGURANÇA DE PROCESSOS NOS CURSOS DE GRADUAÇÃO EM ENGENHARIA QUÍMICA NO BRASIL - UMA VISÃO PRELIMINAR
}

\author{
L.C. MOREIRA ${ }^{1}$, C. A. VAZ JUNIOR ${ }^{1}$ \\ ${ }^{1}$ Universidade Federal do Rio de Janeiro, Escola de Química \\ E-mail para contato: cavazjunior@eq.ufrj.br
}

\begin{abstract}
RESUMO - Segurança de processos é tópico fundamental durante o projeto ou operação de plantas industriais, fazendo parte da atuação profissional do engenheiro químico. Apesar da elevada preocupação com o gerenciamento de risco, o ensino de segurança nos cursos de graduação ainda não se encontra consolidado. O objetivo deste trabalho foi promover este debate. Foram discutidas soluções como: adoção de uma disciplina específica sobre segurança de processos e adoção de disciplina sobre higiene e segurança do trabalho. A adoção de uma visão integrada de segurança de processos em diferentes disciplinas ao longo do curso, ou seu tratamento durante o TCC, também são opções que precisam ser avaliadas. Observa-se que um número cada vez maior de IES incorpora conceitos de segurança no currículo de graduação em engenharia química. Independentemente da solução adotada, a incorporação dos conceitos de segurança pelas IES mostra um alinhamento do meio acadêmico com as demandas sociais, visando promover uma atuação mais responsável e correta por parte dos profissionais da área química.
\end{abstract}

\section{INTRODUÇÃO}

Os grandes acidentes ocorridos ao longo da história da indústria química mundial elevaram a preocupação da sociedade, empresas e governos sobre os riscos destas operações. O emprego de altas pressões, elevadas temperaturas e um grande número de substâncias perigosas (tóxicas, inflamáveis ou explosivas) tornam obrigatórios os investimentos em segurança de processos. A sustentabilidade do setor a médio e longo prazo passam pelo desenvolvimento de plantas cada vez mais seguras.

No mesmo sentido do desenvolvimento de processos cada vez mais seguros, existe a necessidade de consolidar o ensino de segurança de processos no curso de engenharia química. O objetivo deste estudo é, por tanto, promover o debate sobre o tema, apontando diferentes opções de caminhos que já vem sendo trilhados por IES.

\section{ESTRUTURA CURRICULAR}

No Brasil, a estrutura curricular dos cursos de bacharelado em Engenharia Química segue eixo comum instituído pela Resolução CNE/CES 11, de 11 de março de 2002 (MEC,2002). Embora todos sigam uma diretriz única, existem particularidades quando cursos 
de diferentes Instituições de Ensino Superior (IES) são comparados. É frequente observar cursos de engenharia química com maior ou menor foco em petróleo, biotecnologia, indústria de alimentos, papel e celulose ou têxtil. As diferenças refletem, dentre outros fatores, o contexto histórico de criação e evolução do curso na IES. Particularidades como características do quadro docente da IES, sua maior ou menor vocação para pesquisa, existência de programas de mestrado e doutorado, e interação com o mercado de trabalho, certamente influenciam na estrutura da grade curricular.

Embora diferenças existam, a grade curricular da maior parte dos cursos de engenharia química se divide em: "ciclo básico" e "ciclo profissional". O "ciclo básico" ocupa os dois primeiros anos de curso. É composto das disciplinas fundamentais para a formação do engenheiro, tais como cálculo, física e química. Na sequência o aluno ingressa no "ciclo profissional", este com uma duração média de três anos. É durante este tempo que irá cursar disciplinas mais fortemente relacionadas com sua área de atuação profissional. Embora existam variações importantes, em geral o ciclo profissional é composto por disciplinas como: "fenômenos de transporte" (mecânica dos fluidos, transferência de calor e massa), "operações unitárias", "termodinâmica", "modelagem e controle de processos", "projeto de equipamentos", entre outras. O "ciclo profissional" engloba ainda a realização de um estágio e a elaboração de um Trabalho de Conclusão de Curso (TCC).

\section{ENSINO DE SEGURANÇA DE PROCESSOS}

Simultaneamente as questões de ética, responsabilidade social e meio ambiente, a segurança de processos também deve compor o currículo do engenheiro químico atual. Contudo, o documento com as Diretrizes Curriculares Nacionais (MEC, 2002), não cita, explicitamente, o tema "segurança de processos", fazendo menção unicamente a "Ergonomia e Segurança do Trabalho" (página 3, MEC, 2002). Mesmo não constando nas Diretrizes do MEC, diversas IES passaram a enfocar conceitos de segurança de processos na graduação. $\mathrm{O}$ tema vem sendo abordado de diferentes modos, seja através de disciplina exclusiva (obrigatória ou eletiva), tratamento transversal ao longo do curso, disciplina sobre segurança ocupacional / segurança do trabalho, ou segurança química.

\subsection{Disciplina Exclusiva Sobre o Tema}

Trata-se de disciplina em geral alocada na parte final do curso, compondo o último ano de formação do aluno. Neste contexto a disciplina toma como base conceitos e princípios desenvolvidos ao longo de todo o curso de graduação. Seu conteúdo programático tem como foco principal o gerenciamento e análise de riscos, podendo se estender ainda para outros assuntos relativos à segurança, tais como a modelagem matemática de vazamentos e simulação da dispersão atmosférica de gases ou vapores tóxicos e/ou inflamáveis. Envolve ainda conceitos específicos sobre toxicologia de agentes químicos e princípios de proteção contra incêndios. Entre outros, os cursos de graduação em engenharia química da USP (disciplina "Prevenção de Perdas") (USP, 2015), e da UFRJ (disciplina "Segurança de Processos e Prevenção de Perdas) (EQ, 2015a), adotam esta abordagem.

Esta abordagem apresenta como vantagem o fato de permitir um maior aprofundamento do tema ao longo das aulas. A segurança de processos é o único foco da disciplina. Simultaneamente, possibilita uma maior especialização e dedicação por parte do docente 
responsável. Ao dedicar-se ao ensino desta disciplina o docente passa a conhecer melhor sua dinâmica, entender na prática como se desenvolve o andamento das aulas, elevando a eficiência.

Como desvantagem pode-se citar a dificuldade por parte dos alunos em integrar o conhecimento construído nesta disciplina com as demais. Ou seja, existe uma tendência de criar uma visão compartimentada sobre disciplinas e conteúdos. Embora presente em outras disciplinas, essa dificuldade é especialmente relevante para o ensino de segurança de processos. Uma análise de risco, por exemplo, precisa se basear em conhecimentos concretos sobre o processo industrial estudado nas disciplinas anteriores.

\subsection{Abordagem Transversal ao Longo do Curso}

Ao invés de adiar a discussão sobre segurança de processos para o último período, contando que os alunos consigam integrar o conhecimento adquirido ao longo do curso, esta abordagem promove o debate ao longo de várias disciplinas do ciclo profissional. Ou seja, segurança passa a integrar o conteúdo programático de disciplinas como fenômenos de transporte, operações unitárias, projeto de equipamentos, etc. Os fundamentos e aplicações destas disciplinas são complementados com conhecimento sobre segurança de processos, promovendo integração.

Se por um lado está abordagem resulta em um caráter interdisciplinar, promovendo uma visão holística do curso, algumas dificuldades precisam ser observadas. Primeiramente no que tange a formação de docentes. Os docentes de diferentes áreas do conhecimento precisam se sentir a vontade para promover debates de alto nível sobre segurança de processos. O elevado conhecimento em uma determinada área do conhecimento, como projeto de reatores químicos, não torna o profissional imediatamente capaz de atuar de modo adequado em segurança de processos (CSB, 2010). Essa dificuldade torna-se ainda maior quando tais docentes foram formados em cursos de graduação que não dispunham de disciplinas de segurança de processos na grade curricular.

A divisão da disciplina entre dois docentes, sendo um especializado em segurança de processos, poderia resolver essa questão. Contudo, na prática, é frequente observar problemas de integração e bom andamento em disciplinas divididas entre dois ou mais docentes. Isso é especialmente verdadeiro quando as avaliações ocorrem em separado.

É preciso ainda avaliar a definição da carga horária estabelecida no conteúdo programático da disciplina. Ou seja, como combinar de modo adequado carga horária de termodinâmica e segurança de processos em uma mesma disciplina? E como garantir que essa divisão seja, na prática, mantida?

Finalmente, é preciso definir em qual disciplina serão apresentados os conceitos e técnicas de análise e gerenciamento de risco, tais como ferramentas de HAZOP, APR, árvore de falhas, etc. A apresentação dessas ferramentas pode afastar-se demais do escopo das demais disciplinas da grade curricular. O curso de graduação da Universidade do Estado do Rio de Janeiro (UERJ) aborda a análise de risco na disciplina "Projetos de Processos na Indústria Química II", uma disciplina obrigatória de último período (UERJ, 2015). Ou seja, o tópico "Análise de Risco" consta, explicitamente, da ementa do TCC. É importante ressaltar, 
contudo, que o escopo do TCC adotado em diferentes IES varia profundamente, de modo que para algumas Instituições está abordagem pode tornar-se difícil ou mesmo inviável.

\subsection{Disciplina Sobre Segurança Ocupacional / Segurança do Trabalho}

Conforme mencionado, as Diretrizes do MEC (MEC, 2002) citam, explicitamente, o tópico "Ergonomia e Segurança do Trabalho". Embora os conceitos de segurança do trabalho sejam amplamente aplicáveis em plantas químicas, à formação do engenheiro de segurança do trabalho no Brasil não foca na segurança de processos químicos. A adoção de disciplinas de "segurança do trabalho" no currículo de graduação não é, por si só, ruim. É apenas necessário complementar seu foco com uma visão de processos químicos. É preciso promover o completo entendimento das diferenças entre "segurança de processos" e "segurança do trabalho". A grade curricular da PUC-PR, por exemplo, apresenta, em seu nono período, a disciplina obrigatória "Higiene e Segurança do Trabalho", com uma carga horária total de 40 horas (PUC-PR, 2015). Abordagem similar é adotada na Universidade Santa Cecília (Universidade Santa Cecília, 2015).

\subsection{Disciplina Sobre Segurança Química}

Recentemente a FUNDACENTRO promoveu debate sobre regulamentação do ensino de "segurança química" nos cursos de engenharia química. A segurança química é definida como "um conceito global, desenvolvido para assegurar a proteção das pessoas e do meio ambiente frente aos riscos decorrentes de todo o ciclo de vida das substâncias" (FUNDACENTRO, 2015). Foi criado o Grupo Técnico de Educação em Segurança Química para: "fomentar ações educativas, promover debates, colher subsídios e apresentar propostas para levar o tema aos currículos das instituições de ensino" (FUNDACENTRO, 2015).

Embora a regulamentação do ensino de segurança química possa, na prática, representar a regulamentação do ensino de segurança de processos, as duas visões não são equivalentes. Do mesmo modo que existem diferenças entre "segurança de trabalho" e "segurança de processos", também existem distinções entre "segurança química" e "segurança de processos".

É importante ainda ter cautela diante de propostas que visam à adoção compulsória de conteúdos na grade curricular. $\mathrm{O}$ excesso de temas obrigatórios pode engessar o currículo, reduzir o grau de liberdade das IES, e elevar o tempo dos alunos em sala de aula.

\section{O CASO DA ESCOLA DE QUÍMICA DA UFRJ}

O curso de graduação em engenharia química da Escola de Química da UFRJ dispõe, atualmente, de disciplina obrigatória na área de segurança de processos (EQ, 2015a). Criada a cerca de 20 anos como disciplina eletiva, posteriormente tornou-se obrigatória para alunos do último ano. A disciplina ocupa um semestre, e apresenta carga horária teórica de 45 horas.

O conteúdo programático foi organizado tomando por base o livro "Chemical Process Safety”, de Daniel A. Crowl e Joseph F. Louvar (CROWL e LOUVAR, 2010). Aborda conceitos de estatística de acidentes, toxicologia, modelagem de vazamentos e dispersão 
atmosférica de gases. Apresenta ainda princípios básicos de prevenção contra incêndios industriais e análise de risco.

Do mesmo modo que o livro, a disciplina apresenta segurança de processos de forma ampla. Seu objetivo é contribuir na formação do profissional engenheiro químico, respeitando as limitações de tempo e a diversidade de interesses por parte dos alunos.

Além da disciplina obrigatória, a Escola de Química da UFRJ também contempla uma série de disciplinas eletivas que se relacionam com segurança de processos. Dentre as eletivas, destacam-se:

a) Incêndios Industriais: Modelagem, Simulação, Prevenção e Combate: disciplina com foco específico em incêndios industriais (EQ,2015b).

b) Fluidodinâmica Computacional: disciplina com elevado uso de ferramentas computacionais, empregando CFD em diferentes campos da engenharia química - inclusive segurança de processos (EQ,2015c).

c) Biossegurança: disciplina voltada para apresentar aos alunos tópicos relacionados ao emprego seguro de material biológico, tanto em nível laboratorial quanto industrial.

Além das disciplinas, a Escola de Química busca oferecer cursos complementares que reforcem e complementem a formação dos alunos. Através de recente parceria com o Center for Chemical Process Safety (CCPS), vinculado ao American Institute of Chemical Engineers (AIChE), a Escola de Química passou a utilizar o material digital do projeto SAChE (Safety and Chemical Engineering Education) (SAChE, 2015). O projeto SAChE disponibiliza uma série de módulos para o ensino de segurança de processos. Estes módulos são elaborados por profissionais de universidades e indústrias norte-americanas. Desde 2013 a EQ é parceira da AIChE neste programa.

\section{CONCLUSÕES}

A partir deste levantamento preliminar é possível observar a existência de diferentes caminhos adotados pelas IES para o ensino da segurança de processos. Enquanto algumas abordam a segurança de processos em seu enfoque mais tradicional, baseando-se no livro de Crowl e Louvar (CROWL e LOUVAR, 2010), outras IES optam pela vertente da Higiene e Segurança do Trabalho, talvez com um viés mais legalista e normativo. Observa-se ainda o emprego do TCC como uma opção para o desenvolvimento de análise de risco, enfocando segurança de processos de forma aplicada. A visão integrada de segurança de processos ao longo de diferentes disciplinas do ciclo profissional é ainda uma outra opção a ser considerada.

Independente do foco adotado, observa-se que um número cada vez maior de IES incorpora conceitos de segurança no currículo de graduação em engenharia química. Mostrase assim um alinhamento do meio acadêmico com as demandas sociais, visando promover uma atuação mais responsável e correta por parte dos profissionais da área química. 


\section{REFERÊNCIAS}

CROWL, D.A., LOUVAR, J.F.; Chemical Process Safety, Fundamentals with Applications. $2^{\mathrm{a}}$ ed. Editora Prentice Hall International, ISBN: 978-0-13-0181176-3, 2010.

CSB; Case Study: Texas Tech University Laboratory Explosion. U.S. Chemical Safety and Hazard Investigation Board. Disponível em: http://www.csb.gov/assets/1/19/csb study ttu_.pdf , 2010.

EQ; Escola de Química da UFRJ, Programa da Disciplina Segurança de Processos e Prevenção de Perdas. Disponível em: http://www.eq.ufrj.br/graduacao/programas/deq/eqe592.pdf , 2015a.

EQ; Escola de Química da UFRJ, Programa da Disciplina Eletiva: Incêndios Industriais: Modelagem, Simulação, Prevenção e Combate. Disponível em: http://www.eq.ufrj.br/docentes/cavazjunior/prog20142i.pdf , 2015b.

EQ; Escola de Química da UFRJ, Programa da Disciplina Eletiva: Fluidodinâmica Computacional. Disponível em: http://tpqb.eq.ufrj.br/ementas/fluidodinamica-computacional/ , 2015c.

FUNDACENTRO; Seminário sobre Educação e Segurança Química. Disponível em: http://www.fundacentro.gov.br/cursos-e-eventos/detalhe-do-evento/2014/7/seminario-sobreeducacao-e-seguranca-quimica, 2015.

MEC; Conselho Nacional de Educação Câmara de Educação Superior Resolução Cne/Ces 11, 11 de março de 2002. Disponível em: http://portal.mec.gov.br/cne/arquivos/pdf/CES112002.pdf, 2002.

PUC-PR; Pontifícia Universidade Católica - Paraná, Grade Curricular do Curso de Engenharia Química. Disponível em: http://www.pucpr.br/graduacao/engquimica/estrutura.php5 , 2015.

SAChE; Safety and Chemical Engineering Education Program. Disponível em: http://www.sache.org/, 2015.

UERJ; Universidade Estadual do Rio de Janeiro, Ementa da Disciplina Projetos de Processos na Indústria Química II. Disponível em: http://www.ementario.uerj.br/ementas/9546.pdf , 2015.

Universidade Santa Cecília; Grade Curricular do Curso de Engenharia Química. Disponível em: http://www.unisanta.br/Graduacao/Engenharia_Quimica , 2015.

USP; Universidade de São Paulo, Programa das Disciplinas da Escola Politécnica, Curso de Engenharia Química: "PQI2502, Prevenção de Perdas". Disponível em: https://uspdigital.usp.br/jupiterweb/obterDisciplina?sgldis $=$ PQI2502\&codcur $=3091 \& \operatorname{codhab}=$ $\underline{110}, 2015$. 